\title{
On Similarities and Differences between Social Informatics and Information Systems
}

\author{
Pertti Järvinen \\ Department of Computer Sciences, University of Tampere, Finland \\ pj@cs.uta.fi
}

\begin{abstract}
Rob Kling strongly advocated the term Social Informatics. He demonstrated that equipment, equipment vendors, technical specialists, upperlevel managers, ICT policies, internal funding, and external grant funding with the people who will use information systems in the course of other work are not simply a static list but are interrelated within a matrix of social and technical dependencies. In Information Systems there has recently been heated debate about the core content of the discipline. In this paper we study whether Social Informatics and Information Systems are similar or not. According to the broad view on Information Systems, they appear quite similar. The few differences we identified are in research approaches, when most Social Informatics researchers use intensive case studies while most Information Systems researchers surveys. Such minor differences do not support the view that these two sciences should have different names. The researchers in both sciences seem to believe that people's behavior can be predicted, but we demonstrate that this is not true. Hence we propose that theories with people as a component must be adjusted accordingly in both sciences.
\end{abstract}

Keywords: social informatics, information systems, dynamic systems, conception of human being, prediction

\section{Introduction}

Social Informatics (SI) as "the interdisciplinary study of the design, uses and consequences of information technologies that takes into account their interaction with institutional and cultural context" [Kling 1999]. The label 'social informatics' emerged from discussions in 1996 within the community of researchers who conduct the kind of research discussed in Kling [1999]. Several social informatics researchers (Phil Agre, Jacques Berleur, Brenda Dervin, Andrew Dillon, Rob Kling, Mark Poster, Karen Ruhleder, Ben Shneiderman, Leigh Star and Barry Wellman)

Please use the following format when citing this chapter:

Järvinen, P., 2006, in IFIP International Federation for Information Processing, Volume 223, Social Informatics: An Information Society for All? In Remembrance of Rob Kling, eds. Berleur, J., Numinen, M. I., Impagliazzo, J., (Boston: Springer), pp. 395-406. 
participated in a workshop at UCLA on social aspects of digital libraries in 1996. The topic was then about 25 years old.

The history of the discipline called Information Systems (IS) is longer. In the journal Management Science the first IS research articles concerning early visions of decision support systems were published in 1956 [Banker and Kauffman 2004]. The proposal for its curriculum was prepared [McKenney and Tonge 1971, Teichroew 1971] and presented by Ashenhurst [1972]. One reason why consideration of IS is now important is based on the lively discussion on its nature recently initiated by Benbasat and Zmud [2003]. A definition of information systems suitable for our purposes is: the effective design, delivery, use and impact of information technology in organizations and society [Gregor 2002].

In both SI and IS there is debate on the boundaries of the discipline, which topics are to be included and excluded. As a preliminary comment, it seems to me that the domains of SI and IS much overlap. Hence it is interesting to identify their similarities and differences.

Neither SI nor IS, in to my opinion, has an adequate conception of people; there is still room for innovations and improvements. In this sense we try to bring Aulin's [1989] self-steering system as a potential model of the human being into the discussion.

In this paper we start with an analysis of some fundamental characteristics of SI. We then briefly review the recent discussion of the nature of IS. Thereafter, we compare SI and IS. Finally, we propose some improvements to both.

\section{Social Informatics (SI)}

In a section of the Rob Kling Center of Social Informatics (SI) portal [2005] it is claimed that "SI studies aim to ensure that technical research agendas and system designs are relevant to people's lives. The key word is relevance, ensuring that technical work is socially-driven rather than technology-driven. Relevance has two dimensions: process and substance. Design and implementation processes need to be relevant to the actual social dynamics of a given site of social practice, and the substance of design and implementation (the actual designs, the actual systems) need to be relevant to the lives of the people they affect. SI sets agendas for all the technical work in two ways: 1) more superficially, by drawing attention to functionalities that people value, thus setting priorities for design and implementation; and 2) more fundamentally, by articulating those analytical categories that have been found useful in describing social reality, and that which therefore should also define technical work in/for that reality as well. Unfortunately, many technical professionals have viewed social concerns as peripheral. One key role of SI is to stand things back on their feet, so that social concerns are central and define the ground that technical work stands on [Phil Agre, 1996]."

Kling [1999] describes how the professional systems designer oriented to social informatics could design a new system. "A systems designer with a socio-technical orientation does not simply consider these elements while working in a 'design studio' far away from the people who will use a specific system. Effectively 
designing socio-technical systems also requires upon a set of 'discovery processes' to help the designers understand which features and tradeoffs will most appeal to the people who are most likely to use the system. There are a number of discovery processes for learning about the preferences of the men and women who are likely to use these systems. These discovery processes include workplace ethnography, focus group, user participation in design teams, and participatory design strategies. These approaches differ in many significant ways, such as the contextual richness of the understandings that they reveal and the extent to which they give the people who will use systems influence and power in their design. These issues are the subject of a lively body of research that overlaps social informatics."

Kling [2000] writes that "as we develop more elaborate ICTs and try to use them in almost every sphere of social life, we face fresh theoretical challenges for social informatics. Its possibilities and value are illustrated by some of key ideas: 1) the social shaping of ICTs, 2) the conceptions of highly intertwined socio-technical networks, 3) roles of social incentives in energizing new electronic media, and 4) the conceptualization of ICT infrastructure as socio-technical practices and resources."

First, to set the groundwork for socio-technical networks, Kling [2000] starts with a more general concept, that ICT, in practice, is socially shaped. In the standard (non-social informatics) accounts of ICT and social change, it is common to hear information technologies characterized as tools, and questions are asked about their social impacts. To take a wider perspective, the combination of equipment, people, governance structures, and ICT policies is called "the local computing package" [Kling 2000].

Secondly, the local computing package is also an example of a socio-technical network. A socio-technical network brings together equipment, equipment vendors, technical specialists, upper-level managers, ICT policies, internal funding, and external grant funding with the people who will use information systems in the course of other work (such as policing, accounting, taxing, or planning) [Kling 2000]. These elements are not simply a static list but are interrelated within a matrix of social and technical dependencies.

Thirdly, one key idea of social informatics research is that the social context of information technology development and use plays a significant role in influencing the ways in which people use information and technologies, and thus affects the consequences of the technology for work, organizations, and other social relationships. Social context can be characterized by particular incentive systems for using, organizing and sharing information in different work groups and work roles [Kling 2000].

Finally, workable computer applications are usually supported by a strong sociotechnical infrastructure [Kling 2000]. The surface features of computer systems are the most visible and are the primary subject of debates and systems analyses. But they are only one part of computerization projects. Many key parts of information systems are neither immediately visible nor interesting in their novelty. They include technical infrastructure such as reliable electricity. They also involve a range of skilled support - from people to documents system features and training people to use them, to rapid-response consultants who can diagnose and repair system failures. 


\section{Information Systems (IS)}

In his historical review Davis [2000] stated that "the academic field of information systems has developed because organizations use a specialized body of knowledge about information and communication systems. Teaching and research support these organization needs. The field may be defined in terms of observed information systems in organizations and also in terms of the function or field of activity for system planning, development, management, and evaluation. Since the systems deal with capture, repositories, processing, and communication of data, information and knowledge, these are also defined. - Conceptual foundations for the field are set of concepts and propositions that explain why structures are designed the way they are, tasks are scheduled and accomplished in the way they are, and activities are performed the way they are."

Benbasat and Zmud [2003] were concerned that the IS research community is making the discipline's core identity ambiguous by, all too frequently, underinvestigating phenomena intimately associated with IT-based systems and overinvestigating phenomena distantly associated with IT-based systems. They discussed why establishing an identity for the IS field is important. They conceptualize the IT artifact (see Figure 1) as the application of IT to enable or support some task(s) embedded within a structure(s) that itself is embedded within a context(s).

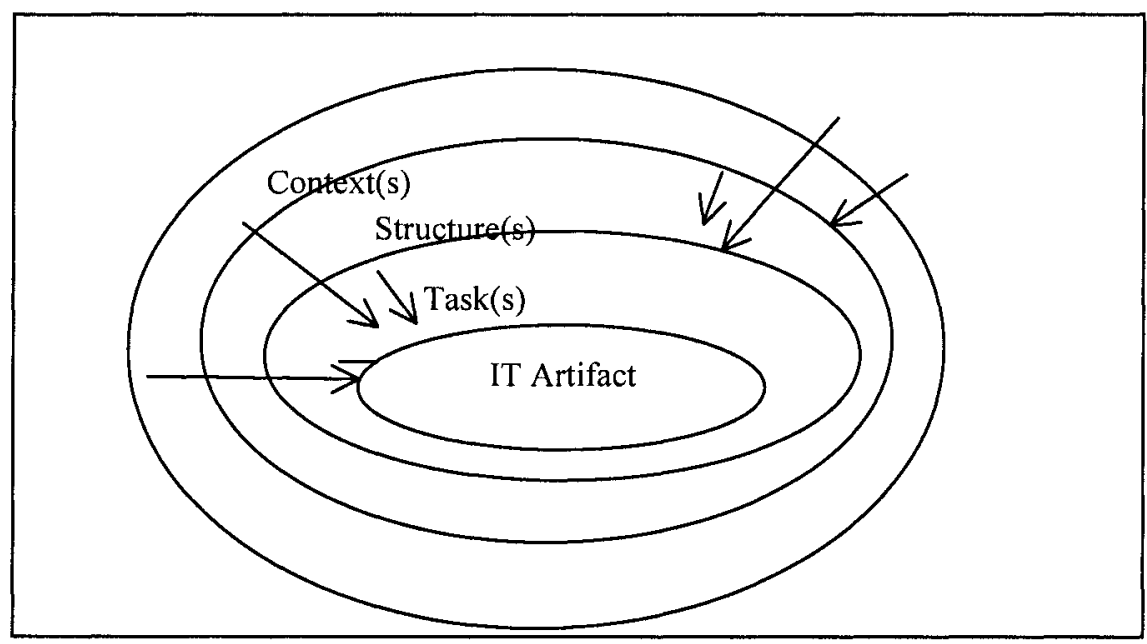

Fig. 1. The IT Artifact

They then described what such an identity might look like by proposing a core set of properties, i.e., concepts and phenomena, that define the IS field.

Benbasat and Zmud's view (Figure 2) of the phenomena studied by IS scholars and hence the set of core properties of the IS discipline includes:

- The managerial, methodological, and technological capabilities as well as the managerial, methodological, and operational practices involved in planning, designing, constructing, and implementing IT artifacts. 
- Human behaviors reflected within, and induced through both the (1) planning, constructing, and implementing, and (2) direct and indirect usage of these artifacts.

- The managerial, methodological, and operational practices for directing and facilitating IT artifact usage and evolution.

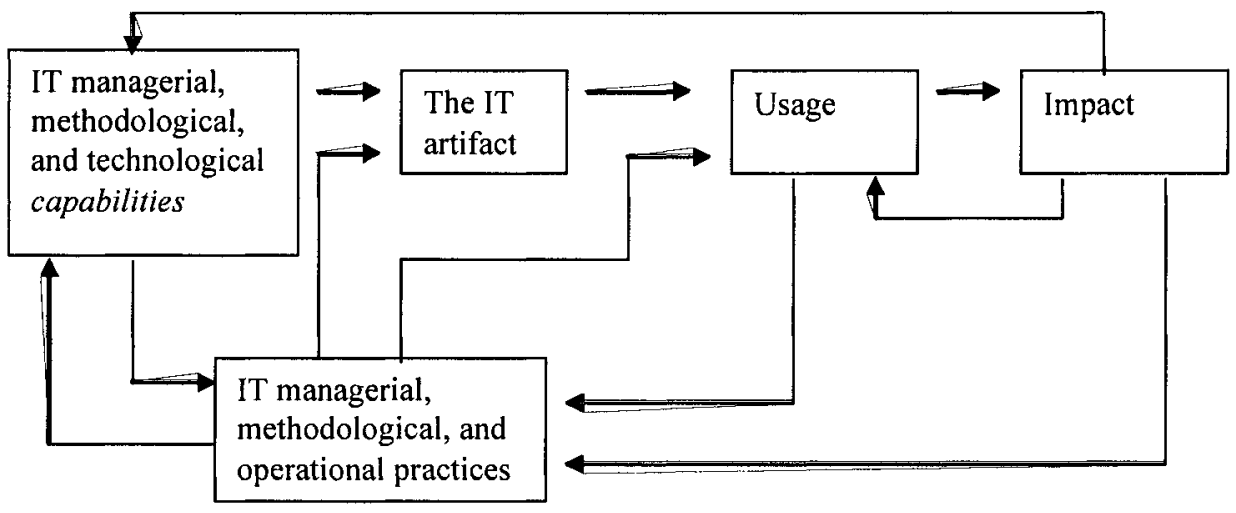

Fig. 2. IT artifact and its immediate nomological net

- As a consequence of use, the impacts (direct and indirect, intended and unintended) of these artifacts on the humans who directly (and indirectly) interact with them, the structures and contexts within which they are embedded, and associated collectives (groups, work units, organizations).

Next, Benbasat and Zmud [2003] discussed research by IS scholars that either fails to address this core set of properties (labelled error of exclusion) or that addresses concepts/ phenomena falling outside this core set (labelled error of inclusion). They concluded by making three suggestions for redirecting IS scholarship toward the concepts and phenomena that they argued define the core of the IS discipline:

- "Does a study investigate the relationships that fall within the IS nomological net - that is, investigate relationships involving one or more of the constructs included in Figure 2?

- How many degrees of separation are there between the IS constructs and the key consequent construct(s) in a study's research model - that is, how far outside the boundaries of the nomological net shown in Figure 2 are the primary constructs being investigated? (Here, by primary constructs we refer to those constructs associated with a study's principal scholarly contribution.)

- What is the nomological density of the IS constructs in a study's research model - that is, do relationships involving only IS constructs represent a majority of the relationships in a research model? To measure nomological density, count the number of two-way relationships among the constructs in the research model that fall within the nomological net (i.e., those relationships that exist between 
constructs in Figure 2), then divide this total by the total number of two-way relationships in the research model."

Agarwal and Lucas [2005] wrote that "since the publication of Benbasat and Zmud's [2003] article, the response from the IS community has been heartening. Many scholars have elected to engage in this debate and offer their perspectives on the field. As might be expected, these commentaries and perspectives offer divergent views on a variety of issues raised by Benbasat and $\mathrm{Zmud}$, such as the existence of a crisis, the need for a defined core for the IS field, and recommendations for the nature of this core." Agarwal and Lucas summarize the key assertions made in the 18 articles.

Agarwal and Lucas [2005] presented an alternative view of the Information Systems identity crisis recently described by Benbasat and Zmud. Agarwal and Lucas agreed with many of their observations, but Agarwal and Lucas were concerned with their prescription for IS research. Agarwal and Lucas criticized their discussion of errors of inclusion and exclusion in IS research and highlighted the potential misinterpretations that are possible from a literal reading of their comments. Agarwal and Lucas' conclusion is that following Benbasat and Zmud's nomological net will result in a micro focus for IS research. The results of such a focus are potentially dangerous for the field. Agarwal and Lucas "classify research that has a narrow focus as micro while they consider research on the transformational aspects of IT as more macro in focus. Agarwal and Lucas' distinction between micro and macro research parallels that drawn in the organizational sciences where micro research is generally viewed as being at the individual or group level of analysis, while macro research focuses on organizations, environments, and strategy. Agarwal and Lucas include work related solely to the IT artifact in the former category. To the extent that macro research seeks to understand how technology is changing organizations, environments, and strategy, they label such research as transformational (my emphasis) in nature."

Agarwal and Lucas present an alternative set of heuristics that can be used to assess what lies within the domain of IS scholarship. They offer the following three questions to help determine if research is relevant to the IS field: (1) "Is there a nontrivial aspect of underlying theory that draws upon the unique nature of the IT artifact? (2) Would the phenomenon have been approached differently were the IT artifact not involved? (3) Does the research illuminate scholarly and practitioner understanding related to the construction, management, and effects of the IT artifact?" Agarwal and Lucas argue that the IS community has a powerful story to tell about the transformational impact of information technology. They believe that a significant portion of our research should be macro studies of the impact of IT. It is important for academic colleagues, deans, and managers to understand the transformational power of the technology. As IS researchers with a profound knowledge of the underlying artifact, we are best positioned to undertake such research. 


\section{Comparison of SI and IS}

To start our comparison we would first like to refer to differences between standard tool models and socio-technical models identified by Kling and Lamb [1999].

To our mind, Benbasat and Zmud [2003] had some kind of tool model in mind, but Agarwal and Lucas [2005] and their ideas are closer to socio-technical models. They mentioned that "Figure 1 in Benbasat Zmud presents the IT artifact as embedded within a structure and context, with arrows running from contexts to structure to tasks to the IT artifact. Agarwal and Lucas' view inserts a set of arrows running in the opposite direction as well; the IT artifact has had a dramatic impact on tasks, structures, and the context of organizations and industries." - Roberta Lamb [2005] noted that IS researchers often perform their studies with 'management' in mind but SI researchers expect a wider audience for their studies.

Table 1. Conceptions of ICT in organizations/society

\begin{tabular}{ll}
\hline Standard (tool) models & Socio-technical models \\
\hline ICT is a tool & ICT is a socio-technical network \\
A business model is sufficient & An ecological view is also needed \\
One-shot ICT implementations are made & ICT implementations are an ongoing social \\
& process \\
Technological effects are direct and & Technological effects are indirect and involve \\
immediate & different time scales \\
Politics are bad or irrelevant & Politics are central and even enabling \\
Incentives to change are unproblematic & Incentives may require restructuring (and \\
Relationships are easily reformed & may be in conflict) \\
Social effects of ICT are big but isolated and & Relationships are complex, negotiated, \\
benign & multivalent (including trust) \\
Contexts are simple (a few key terms or & Potentially enormous social repercussions of \\
demographics) & ICT (not just quality of work life, but overall \\
Knowledge and expertise are easily made & quality of life) \\
explicit & Contexts are complex (matrices of \\
ICT infrastructures are fully supportive & businesses, services, people, technology \\
& history, location, etc.) \\
& Knowledge and expertise are inherently \\
& tacit/implicit \\
& Additional skill and work are needed to make \\
& ICT work \\
\hline
\end{tabular}

Agarwal and Lucas extended Benbasat and Zmud's definitions of 'impact' and 'IT artifact'. The nomological net in Benbasat and Zmud's Figure 2 includes a variable called 'impact', which is defined to be the (direct or indirect, intended or unintended) impact of these artifacts on humans who directly (and indirectly) interact with them, structures and contexts within which they are embedded, and associated collectives (groups, work units, organizations) (p. 186). It is possible that Benbasat 
and Zmud agree with Agarwall and Lucas' call for macro research, given the inclusion of the impact variable in their nomological net. However, their paper does not suggest a need for macro-oriented research, nor does it discuss the transformational nature of information technology. In particular, the impact (or a new set of variables) should include the transformation of industries, firms, and individual tasks as well as new bases for competition and new business models. Agarwal and Zmud recommend expanding the definition of the IT artifact from "enabling or supporting some tasks" to specify IT as the integration of the processing logic found in computers with the massive stores of databases and the connectivity of communications networks. The IT artifact includes IT infrastructure, innovations with technology, and especially the Internet.

Kling [1999] describes the use of socio-technical systems as follows: "As sociotechnical systems, we can pay special attention to:

- people in various roles and relationships with each other and with other system elements;

support resources (training/support/help); and

- information structures (content and content providers, rules/norms/regulations, such as those that authorize people to use systems and information in specific ways, access controls).

He asks about the importance of their content for various constituencies, who is authorized to change content and how that matters, etc." He adds

- "The networks' content for various constituencies, who is authorized to change content, and how that matters." [Kling 2000].

In the list above there are many such elements that connect technological artifacts to their social world. To our mind, the relationships between technological artifacts and social world in Social Informatics as described by Kling are much richer than in Information Systems as described by Benbasat and Zmud, and by Agarwal and Lucas, too.

\section{Some Ideas to Supplement Both SI and IS}

So far the human being has only been implicitly considered, and writers in both Social Informatics and in Information Systems supported the macro view. We shall below analyze some characteristics of the human being. Our motivation in so doing is based on two disparate views. First, Hevner et al. [2004, p. 82] indirectly define IT artifact: "We include not only instantiations in our definition of the IT artifact but also the constructs, models, and methods applied in the development and use of information systems. We do not include people or elements of organizations in our definition nor do we explicitly include the process by which such artifacts evolve over time." In addition, Alter [2003] criticizes Benbasat and Zmud's idea to take the IT artifact as core concept of information systems, its main role in their nomological net (Figure 2). He starts by examining the meaning of 'IT artifact' and concluding that this term is too unclear to serve as a basic concept for delineating the field. "The concept of work system is useful in trying to interpret Benbasat and Zmud's definition of IT artifact. A work system can be defined as a system in which human 
participants and/or machines perform work using information, technology, and other resources to produce products and/or services for internal or external customers. A rudimentary understanding of a work system requires a basic description of those six underlined elements in the definition plus some understanding of three additional elements: the relevant environment, infrastructure, and strategies." To this end we pose the question: Why do Hevner et al. not want to include people into their definition? Is there something problematic about people for building information systems?

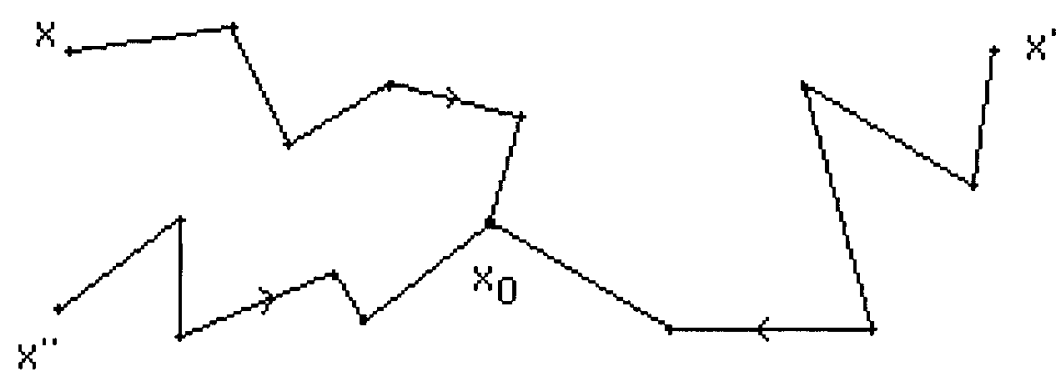

Fig. 3. A nilpotent dynamic system

We consider information systems as dynamic systems and we use Aulin's [1989] classification of those systems. Aulin [1989] states that the initial state $\mathrm{x}_{0}$ is called the rest state and the nilpotent dynamic system (Figure 3 ) has the property that it comes back to its initial state after a finite number (s) of units of time. A dynamic system with a full causal recursion does not have any rest state to be reached in a finite number of steps (in a finite time). The causal systems can be classified to two categories: nilpotent systems and systems with a full causal recursion.

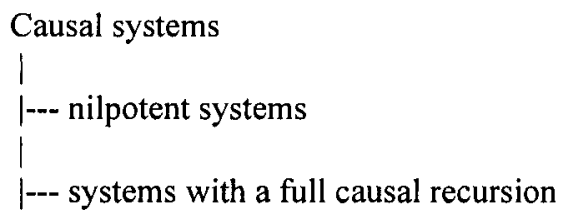

The causal systems with full causal recursion can be divided into four classes depending on whether the system will disintegrate after a certain disturbance and its trajectory disassociate from the path of its old goal function, or whether the system is steerable from outside and its path goes in the constant distance of the path of its old goal function or comes closer to the path of its old goal function in time. The latter can be either finite (self-regulating systems) or infinite (self-steering systems). 


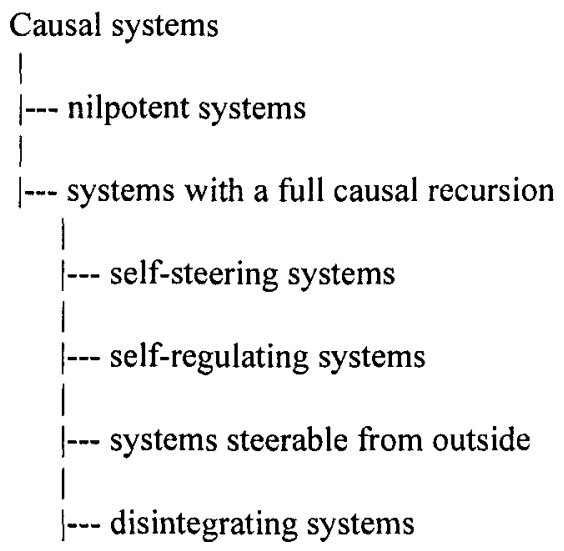

If the uniqueness of the states of mind, along with the goal-oriented nature of thought processes, is typical of human consciousness, the only thinkable causal representation of what takes place in the human mind in an alert state is the selfsteering process. According to Aulin $[1989,173]$ it is, however, necessary to limit the interpretation so that what is self-steering in the human mind is the total intellectual process. Not all the partial processes need be self-steering.

Real-world examples of self-regulating systems are: a room equipped with a good thermostat (self-regulating equilibrium systems); some living organisms like a heart (periodically pulsating self-regulating systems); etc. A flying ball (the resistance of the air is negligible), a frictionless oscillator and a robot are examples of systems steerable from outside. A radioactive atom and a dead organism are disintegrating systems.

Aulin's classification gives us a partial explanation for the exclusion of people made by Hevner et al. All the components (e.g. hardware, software and data as nilpotent systems) of the IT artifact are then behaving regularly, because people as self-steering sub systems whose behavior cannot be predicted do not belong to the IT artifact.

But what does the combination of hardware, software and data as nilpotent sub systems, and people as self-steering sub systems mean for the practice (design, use and management) of information systems?

Design: use the participative development method, allow people to design their jobs themselves; base the distribution of tasks between people and computer on the novice user, develop flexibilities for the computerized sub system for the expert user.

Realization: Because people learn some tasks, allow them to move their routine tasks to the flexible computerized sub system, i.e. allow them to change the distribution of tasks between people and computer.

Management: Apply process innovations, i.e. integrate consecutive tasks into one job; reduce unnecessary hierarchies (The Law of Requisite Hierarchy in [Aulin 1989]).

What does the combination nilpotent and self-steering sub systems mean for the science (research) of information systems? 
People: Repetitive research settings are not allowed, because a human being is always moving into a new state. Gather data by asking human subjects; confirm raw data by triangulation, apply Klein and Myers's [1999] principles.

IT artifacts: Apply Orlikowski and Iacono's [2001] five premises. Follow the seven guidelines of Hevner et al.'s [2004].

\section{Discussion}

Researchers in Social Informatics do not want to use research models typical for the controlled experiment where one independent variable is manipulated and its influence on the dependent variable is studied when all the other variables are kept constant or carefully controlled. The testing of a certain theory or theoretical framework in wide surveys is not typical for social informatics researchers who "study specific ICTs in specific settings to develop concepts and theories that apply to many kinds of ICTs in many kinds of settings" [Kling 2000]. Information systems researchers, too, seek knowledge applicable to many contexts, but, to my mind, their research models are narrower than the models of social informatics researchers, because surveys play a central role in IS studies [Orlikowski and Baroudi 1991]. Social informatics researchers prefer more realistic research models of the matrix of social and technical dependencies.

According to Gregor and Jones [2004] Information Systems (IS) as a discipline is concerned with action - the design, construction and use of software and systems involving people, technology, organizations and societies. In acting in building information systems it is preferable not to approach every new development problem afresh. We would like some guiding knowledge that can be transferred from one situation, in which action is taken, to another. Generalized knowledge of this type can be referred to as design theory. In Information Systems people are considered to behave in a similar way to technology, i.e. regularly. The purpose of Social Informatics is "to understand how people's behavior can help scientists develop empirically-grounded concepts that help scientist to predict (or at least understand) variations in the ways that people and groups use information technologies" [Kling 1999]. But we demonstrate here that because of free will, people do not always behave regularly or predictably, and hence both Social Informatics and Information Systems must be improved by new, more realistic models of the human being.

\section{References:}

R. Agarwal and H. C. Lucas Jr, The Information Systems Identity Crisis: Focusing on HighVisibility and High-Impact Research, MIS Quarterly 29(3), 381-398, 2005.

P. Agre, Toward a Critical Technical Practice: Lessons Learned in Trying to Reform Al, in: Bridging the great divide: Social science technical networks, and cooperative work, edited by Bowker, Gasser, Star and Turner, Erlbaum 1996) 
S. Alter, Sidestepping the IT Artifact, Scrapping the IS Silo, and Laying Claim to 'Systems in Organizations', Communications of the Association for Information Systems 12(30), $54 \mathrm{p}$ [2003.

R.L. Ashenhurst, A Report of the ACM Curriculum Committee on Computer Education for Management, Communications of the ACM 15(5), 363-398 [1972.

A. Aulin, Foundations of Mathematical System Dynamics: The Fundamental Theory of Causal Recursion and its Application to Social Science and Economics, Pergamon Press, Oxford, 1989.

R.D. Banker and R.J. Kauffman, The Evolution of Research on Information Systems: A Fiftieth-year Survey of the Literature in Management Science, Management Science 50(3), 281-298, 2004.

I. Benbasat and R.W. Zmud, The Identity Crisis within the IS Discipline: Defining and Communicating the Discipline's Core Properties, MIS Quarterly 27(2), 183-194, 2003.

G. B. Davis, Information Systems Conceptual Foundations: Looking Backward and Forward, in: Organizational and Social Perspectives on Information Technology, edited by R. Baskerville, J. Stage and J. DeGross, Kluwer, Boston. 2000, pp. 61-82.

S. Gregor, Design Theory in Information Systems, Australian Journal of Information Systems, Special Issue, 14-22, 2002.

S. Gregor and D. Jones, The Formulation of Design Theories for Information Systems, in: Constructing the infrastructure for the knowledge economy: Methods and tools, theory and practice, edited by Linger, Fisher, Wojtkowski, Zupancic, Vigo and Arold, Kluwer Academic, New York, 2004, pp. 83-93.

A.R. Hevner, S.T. March, J. Park and S. Ram, Design Science in Information Systems Research, MIS Quarterly 28(1), 75-105, 2004.

H.K. Klein and M.D. Myers, A Set of Principles for Conducting and Evaluating Interpretive Field Studies in Information Systems, MIS Quarterly 23(1), 67-94, 1999.

R. Kling, What is Social Informatics and Why Does it Matter?, D-Lib Magazine 5(1), 1-22, 1999.

R. Kling, Learning about Information Technologies and Social Change: The Contribution of Social Informatics, The Information Society 16(3), 217-232, 2000.

Rob Kling Center of Social Informatics portal, History of the Term, (http://rkcsi.indiana.edu/article.php/about-social-informatics/35 , November 7, 2005)

R. Kling and R. Lamb, IT and Organizational Change in Digital Economies: A Sociotechnical Approach, in: Understanding the Digital Economy - Data, Tools and Research, edited by Kahin and E. Brynjolfsson, MIT Press, Cambridge MA, 1999; http://mitpress.mit.edu/ude.html

R. Lamb [2005], A Private Communication, December 1, 2005 at Turku, Finland.

J.L. McKenney and F.M. Tonge, The State of Computer Oriented Curricula in Business Schools 1970, Communications of the ACM 14(7), 443-448, 1971.

W.J. Orlikowski and J.J. Baroudi, Studying Information Technology in Organizations: Research Approaches and Assumptions, Information Systems Research 2(1), 1-28, 1991.

W.J. Orlikowski and C.S. Iacono, Research Commentary: Desperately Seeking the 'IT' in IT Research - A Call to Theorizing the IT Artifact, Information Systems Research 12(2), 121134, 2001.

D. Teichroew, Education Related to the Use of Computers in Organizations, Communications of the ACM 14(9), 573-588, 1971. 